\title{
Archives on Veterinary Science and Technology
}

Hong W, et al. Arch Vet Sci Technol: AVST-141.

\section{Staphylococcal Enterotoxins Modulated the Porcine Toll-Like Recep- tor Transcription and Medicated Inflammatory Response}

\author{
Wenjiao Hong, Lilin Zhang, Pei Chen, Songbao Dai, Yihe Xia, Jinhai Huang*, Lei Zhang* \\ School of School of Life Sciences, Tianjin University, Tianjin, China
}

"Corresponding author: Jinhai Huang, School of Life Sciences, Tianjin University, Tianjin 300072, China. No. 92, Weijin Road, Nankai District, Tianjin, 300072, China. Tel: +862227402902; Email: jinhaih@tju.edu.cn

Citation: Hong W, Zhang L, Chen P, Dai S, Xia Y, et al. (2018) Staphylococcal Enterotoxins Modulated the Porcine Toll-Like Receptor Transcription and Medicated Inflammatory Response. Arch Vet Sci Technol: AVST-141. DOI: 10.29011/AVST-141. 100041

Received Date: 02 January, 2018; Accepted Date: 08 January, 2018; Published Date: 19 January, 2018

\begin{abstract}
Toll-Like Receptors (TLRs) are a family of pattern recognition receptors that are an important link between innate and adaptive immunity. In this study, we cloned all 10 porcine TLR genes. A large number of nonsynonymous Single Nucleotide Polymorphisms (SNPs) are possessed by the ectodomain of porcine TLR gene that codes sequences to increase pathogen recognition's variability in pig populations. Based on the foregone crystal structure of human TLRs and homologous modeling analysis, the three-dimensional structures for the ECD of porcine TLR1-10 were predicted to understand the receptor-ligand interaction sites and the regulation mechanisms of TLR signaling. All the TLRs proteins have a characteristic horseshoe-like solenoid structure; a central $\beta$-sheet provided by the LxxLxLxxN motifs constitutes the concave and $\alpha$ helices or loops constitute the convex part of the structure. The TLR transcripts from PAM cells treated by staphylococcal enterotoxin in vitro and PBMCs isolated from staphylococcal enterotoxin intraperitoneal inoculation pigs were detected by qRT-PCR, the results indicated that cell surface TLRs (TLR1/2/6/10) and endosomal TLRs (TLR3/7/8/9) might have distinct roles in response to extracellular staphylococcal enterotoxins. The transcription levels of chemokine receptor CCR2 and cytokines (GM-CSF, TNF- $\alpha$, MCP-1, IL-1 $\beta$ ) were up-regulated after staphylococcal enterotoxin treatment. Our results showed that the porcine cell surface TLR1/2/6/10 play crucial roles in modulates inflammatory responses to Super Antigens (SAG). It is important for further study on ligand specificity and signaling pathways of porcine TLRs.
\end{abstract}

Keywords: Gene Polymorphism; Phylogenetic Analysis; Porcine; Toll-Like Receptor; TLR Dimers

\section{Introduction}

Surface-localized Pattern Recognition Receptors (PRRs) can mediate immune system and response to Pathogen-Associated Molecular Patterns (PAMP) that ultimately burns typically results in disease resistance. Toll-Like Receptors (TLRs) are the most typical in families of PRRs. As of now, there are at least 15 TLRs reported $[1,2]$. Ten human TLRs (TLR1-TLR10) have been classified and 12 in mouse (TLR1-9, TLR11-13). TLR14 and TLR15 have been found in mouse and chicken respectively. Report has shown that human cells also express TLR14 [3]. Toll encodes for a type I integral membrane protein with a large N-terminal extracellular domain consisting of a series of Leucine-Rich Repeats (LRRs) flanked by cysteine-rich motifs. The cytoplasmic intracellular Cterminal domain shares significant similarities with the mammalian interleukin-1 receptor and thus is termed the Toll-Interleukin Receptor (TIR) domain [4,5]. Extracellular domain recognizes Pathogen Associated Molecular Parents (PAMPs); subtle changing of its spatial structure can largely affect ligand recognition. N-terminal cytoplasmic tail is consisted with Toll-IL-1 Receptor (TIR) domain, the TIR signaling domains are highly conserved, which assures stabilized signal transduction [6]. Sequence comparisons indicate that all TLR family proteins have similar domain arrangements, with a single transmembrane helix connecting the extracellular ligand-binding domain to the intracellular signaling domain, extracellular domain has remarkable homology variability, indicating extracellular domain binds either directly to ligands or to coreceptor-ligand complexes [7-9], and it mediates multimerization of the receptor, launching a signaling cascade and activating the innate and adaptive immune system [10,11]. TLR1, 2, 4, 5, 6 and 10 are cell-surface Toll-like receptors, primarily recognize microbial products $[12,13]$, such as peptidoglycan, lipoteichoic acid. TLR4 and TLR5 recognize Lipopolysaccharide (LPS) and flagellin respectively. TLR3, 7, 8 and 9 are located within the cytoplasm whereas the bacterial and viral sensors [14], TLR3 recognize alien double-stranded RNA, TLR7, 8 recognize single-stranded RNA, and TLR9 detects CpG oligodeoxynucleotide DNA. By binding with ligands, TLRs form homodimer or heterodimer (most of them 


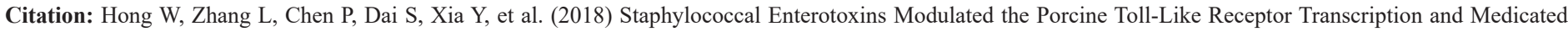
Inflammatory Response. Arch Vet Sci Technol: AVST-141. DOI: 10.29011/AVST-141. 100041

are homodimers except TLR1-TLR2, TLR2-TLR6 are heterodimers), processing recruitment of these signaling adapters through heterotypic TIR-TIR interactions $[3,15,16]$.

Although significant progress has been built the function of TLRs and their connecting with disease resistance and susceptibility in man over the past few years $[17,18]$, relatively little is known about the contribution of TLRs to successful host defense in porcine. The full-length cDNA sequences for all 10 porcine TLR genes are obtainable in our lab; we observed species-specific differences in recognition of TLR ligands such as single-stranded RNA, bacterial DNA and flagella, these distinctions show the different selective pressure presumably on every host to become used to pathogens and new surroundings. As the primary task towards conducting detailed studies the function of TLR and the interactions of host-pathogen in porcine, we have cloned the coding sequences of porcine TLRs 1-10. Crystal structure for porcine TLRs is not yet available, but there are several proteins possessing domains of sufficiently high homology, this enabled us to establish models of the TLRs. Here, the TLR transcripts from PAM cells treated by recombinant staphylococcal enterotoxin in vitro and PBMCs isolated from staphylococcal enterotoxin intraperitoneal injection pigs were performed to understand the response of TLRs to super antigens.

\section{Materials and Methods}

\section{Cells and Reagents}

Porcine Alveolar Macrophages (PAM) cells used for this study were originally isolated from 30-day PRRSV-negative pigs provided by Tianjin Animal Center. In vivo experiment, The PAM cells obtained from 4-6 weeks' healthy pig by bronchoalveolar lavage after necropsy, using sterile $0.01 \mathrm{M}$ PBS (0.2\% EDTA, $\mathrm{pH7.0)}$ lavages three times, utilizing 8 layers of gauze filters the liquid,1500r/min centrifuge for $10 \mathrm{~min}$, the pellet was washed two times by sterile $0.01 \mathrm{M}$ PBS, and then resuspended the cells by RPMI-1640 media containing 10\% FBS, penicillin (100 U/mL) and streptomycin $(100 \mathrm{mg} / \mathrm{mL})$ (Sigma, USA). Adjust the cell concentration to $1 \times 10^{6}$ cells per $\mathrm{mL}$ and transfer to six well plate, incubate the cells at $37^{\circ} \mathrm{C}$ in $5 \% \mathrm{CO}_{2}$ incubator. Harvest cells when cell confluence rate reached $90 \%$. All animal infection experimentations were performed under conditions of the conventional animal care facilities and reasonable regulations.

\section{RNA Extraction and cDNA Synthesis}

Total RNA was extracted from the harvest porcine PAM cells using the RNeasy Mini Kit (Invitrogen, USA). RNA yield and quality were measure by utilizing a Nanodrop ND-1000 spectrophotometer (Thermo, USA), cDNA was synthesized utilizing Super Script TM III First-Strand system (Invitrogen, USA), The amplification included an initial denaturing step in a reaction mixture containing $0.5 \mu \mathrm{g}$ RNA, $50 \mathrm{mM}$ oligo-dT ${ }_{18}$ primer and $10 \mathrm{mM}$ $\mathrm{dNTP}$ at $65^{\circ} \mathrm{C}$ for $5 \mathrm{~min}$ to denature RNA, and then, adding the reverse transcription master mix to each sample to amplified target genes in a $20 \mu 1$ reaction mixture that contains $1 \times$ First Strand buffer, $10 \mathrm{mM}$ DTT, $1 \mathrm{ml}$ RNase OUT and 200 units of Superscript III RT. Reactions were incubated at $50^{\circ} \mathrm{C}$ for $1 \mathrm{~h}$, followed by inactivate the RT enzyme activity for $15 \mathrm{~min}$ at $70^{\circ} \mathrm{C}$.

\section{Amplification and Cloning of Porcine TLRs 1-10 Genes}

Primers used for porcine TLR1-10 coding region were designed by Oligo7.0, synthesized by GENEWIZ (USA), as described in (Table 1). $50 \mu \mathrm{L}$ PCR reaction system: $2.5 \mu \mathrm{L}$ cDNA from total RNA reverse transcription as templates, $1 \mu \mathrm{L}$ HiFi Taq DNA polymerase (Transgen, Beijing, China), $5 \mu \mathrm{L} 10 \times$ PCR buffer, $5 \mu \mathrm{L} 2,5 \mathrm{mM}$ dNTPs, $1 \mu \mathrm{L} 10 \mathrm{mM}$ Forward primer and Reverse primer respectively. In order to amplify full length of Porcine TLRs, the method of Gradient PCR was used, temperature cycling as follows: $94^{\circ} \mathrm{C} 5 \mathrm{~min},\left[94^{\circ} \mathrm{C} 30 \mathrm{sec} / 53.5^{\circ} \mathrm{C} 30 \mathrm{sec} / 72^{\circ} \mathrm{C} 30\right.$ sec $] \times 5$ cycles $($ TLR $1,2,4,5,6,10),\left[94^{\circ} \mathrm{C} 30 \mathrm{sec} / 57^{\circ} \mathrm{C} 30 \mathrm{sec} / 72^{\circ} \mathrm{C} 30\right.$ sec] $\times 5$ cycles(TLR $3,7,8,9),\left[68^{\circ} \mathrm{C} 2.5 \mathrm{~min}\right] \times 30$ cycles, $72^{\circ} \mathrm{C} 10$ for minutes at end to allow complete elongation of all product DNA, details of the specific PCR parameters for corresponding gene are visible in (Table 1). Using TIANgel Midi Purification Kit (TIANGEN, Beijing) purifies PCR products. PCR products were ligated with the pEASY-T1 Vector System (Trans Gen Biotech, Beijing), The plasmid containing pEASY-T1 gene was transformed into competence Top10 (Preserved by our laboratory), incubated at $37^{\circ} \mathrm{C}$ in Luria Bertani (LB) with $\mathrm{Amp}^{+}$for $14 \mathrm{~h}$, Plasmid DNA was got by using a Fast Plasmid extraction kit (OMEGA), sequence analysis completed by GENEWIZ (USA).

\section{Bioinformatics Analysis of Porcine TLRs}

Cloned TLRs sequences were analyzed by DNAMAN 8.0 and blasted in GenBank. Mega Blast was used to identify mammalian TLR nucleotide sequences within the non-redundant nucleotide database (http://www.ncbi.nlm.nih.gov/) by comparison with porcine TLR sequence (Supplementary Table 1). Phylogenetic tree was drawn to analyze the evolution history of TLRs. Signal P 4.1 Server-prediction (ExPASy Proteomics Server) (http://expay. org) was employed to predict TLRs signal peptide. The Simple Modular Architecture Research Tool (SMART) (http://smart.embl-heidelberg.de/) and TMHMM Server v2.0 were used to analyze the domain structure of TLRs.

TLRs 1-10 from mammalian species were collected from GENBANK (Supplementary Table 1), multiple alignments of the amino acid sequences for the full lengths, LRR sequences and TIR sequences were performed by using MEGA. Evolutionary rate heterogeneities of LRR and TIR domains within TLRs were estimated by the method of Norio Matsushima, 2012 [19]. Whether the average genetic distance between pairs of LRR sequences is meaningfully distinct from that of TIR sequences within likewise TLR protein, the statistic used to estimate the genetic distances between the LRR and the TIR in each of member of TLR member $\left(\Delta_{T I R-L R R} \Delta_{T I R-L R R}\right)$. 


$$
\begin{aligned}
& \Delta_{T I R-L R R}=\sum_{i<j}\left(T_{i j}-L_{i j}\right) / \frac{n(n-1)}{2}(1) \\
& \Delta_{T I R-L R R}=\sum_{i<j}\left(T_{i j}-L_{i j}\right) / \frac{n(n-1)}{2}(1) \\
& \Delta_{T I R-L R R}=\sum_{i<j}\left(T_{i j}-L_{i j}\right) / \frac{n(n-1)}{2}(1)
\end{aligned}
$$

\section{Homology Remodeling Analysis}

To date, there are no crystallographic structures for porcine TLRs, their ligand-binding mechanisms are poorly understood. According to the templates, TLR1 (2Z7X), TLR2 (1SXT), TLR3 (2AQ3), TLR9 (3OWE) provided by PDB database, tertiary structures of the TLRs have been simulated by homology modeling function of Swiss Model (http://swissmodel.expasy.org/). Online analysis software Predict Protein (https://www.predictprotein. org/) and Swiss-Model (http://swissmodel.expasy.org) were separately applied to predict secondary structure and tertiary structure of porcine TLRs.

If $V_{i j}^{T l R} V_{i j}^{T l R}$ and $V_{i j}^{L R R} V_{i j}^{L R R}$ are assumed to be the same for all of the ij pairs

If $V_{i j}^{T I R} V_{i j}^{T I R}$ and $V_{i j}^{L R R} V_{i j}^{L R R}$ are assumed to be the same for all of the ij pairs

Where " $n$ " is the total number of sequences within a TLRs. $T_{i j}$ and $\mathrm{L}_{\mathrm{ij}}$ are separately

represented estimate the TIR and the LRR 's pairwise genetic distance between the part of sequence $i$ and $j$. To verify the statistical significance of $\Delta_{\text {TIR-LRR }}$, a sampling distribution for the test statistic under the null hypothesis of no difference between evolutionary rates of TIR and LRR domain, was estimated by randomly assigning amino acid positions to the TIR or LRR categories in proportion to the frequency of these categories in the original sequence [19]. As obtained the average difference of original sequences, genetic distances for the new data sets are then estimated. This was done 1000 times, and then the $1000 \boldsymbol{\Delta}$ distribution was used as the sampling distribution. When $\boldsymbol{\Delta}$ falls completely outside of the range of simulated values the probability or $p$ value is less than 1 in $1000(p<0.001)$, and the null hypothesis is rejected. Aligned homo

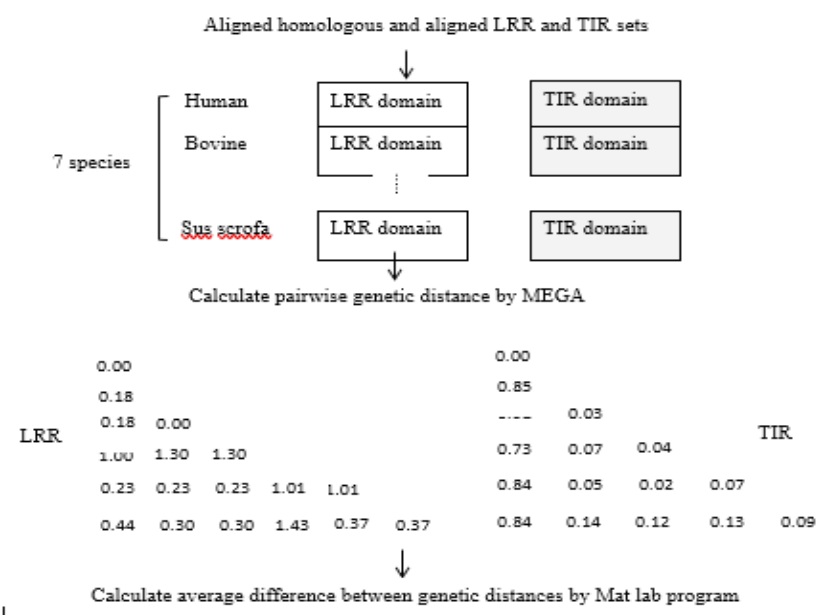

\section{Transcription Change of TLRs on PAMs Stimulated by Staphylococcal Enterotoxins}

Recombinant staphylococcal enterotoxins, rSEK, rSEO were purified as previously described [20]. The PAM cells were isolated from 4-6 weeks' healthy pig, and seeded in 96-well cell plates at $1 \times 10^{6}$ cells/well in $10 \%$ FCS-RPMI-1640 (Gibco, USA). The super antigenic effect was explored by treating PAM cells with 100 $\mathrm{ng} / \mathrm{mL}$ of $\mathrm{rSEO}, \mathrm{rSEK}$ and natural SEA, PHA $(10 \mathrm{ng} / \mathrm{mL})$ as positive control, and PBS buffer as blank control. Four replicates were set for each group with at least three times repeating.

The designated SEs were injected into the 4-6 weeks' healthy pig at a dose of $20 \mathrm{ng} / \mathrm{kg}$ through intraperitoneal injection and 3 pigs in each group got same treat for repeat. The PBMC were collected and isolated from those pig's post-injection of $0,24,48$ and $72 \mathrm{hrs}$.

Total RNAs were extracted from SEs stimulated PBMCs in vivo and PAM cells in vitro by TRIZOL LS (Promega, USA) according to the manufacture's protocol, and reverse-transcripted

by Trans Script First-strand cDNA Synthesis kit (Trans Gen, China). SYBR Green Master Mix (Vazyme) was used according to the manufacturer's instructions and the real-time PCR was performed on a 7500 Real-time PCR system (Applied Biosystems, Foster city, CA, USA). The real-time PCR results were analyzed and expressed as relative expression of CT (threshold cycle) valuing the 2- $\Delta \Delta \mathrm{Ct}$ method [20]. The primer pairs used for qRT-PCR are as (Table 6).

\section{Results \\ cDNA cloning of porcine TLRs}

Specific primers used to clone full length of porcine TLR genes are in (Table 1). 
Citation: Hong W, Zhang L, Chen P, Dai S, Xia Y, et al. (2018) Staphylococcal Enterotoxins Modulated the Porcine Toll-Like Receptor Transcription and Medicated Inflammatory Response. Arch Vet Sci Technol: AVST-141. DOI: 10.29011/AVST-141. 100041

\begin{tabular}{|c|c|c|c|c|}
\hline Gene & Primer Sequence (5'-3') & Accession No. & $\operatorname{Tm}\left({ }^{\circ} \mathrm{C}\right)$ & Size (bp) \\
\hline \multirow{2}{*}{ TLR1 } & F- TACCCTTAGGAATGTCTACTGTTAC & \multirow{2}{*}{ AB086376 } & \multirow{2}{*}{53.0} & \multirow{2}{*}{2442} \\
\hline & R-CCAAAAGCAGCAGAGGAATA & & & \\
\hline \multirow{2}{*}{ TLR2 } & F-ACGGTGTGCTGCAAGGTCAACTCTC & \multirow{2}{*}{ NM213761 } & \multirow{2}{*}{57.9} & \multirow{2}{*}{2433} \\
\hline & R-ATAAAGACCAGCATCGGACCAAGACT & & & \\
\hline \multirow{2}{*}{ TLR3 } & F-TTTCTGCTCTCTAACTACAACC & XM005671739 & 53.0 & 2761 \\
\hline & R-CTTAATGTACTGAATTTCTGGAAC & & & \\
\hline \multirow{2}{*}{ TLR4 } & F-ATGCTTTCTCCGGGTCACTTCT & \multirow{2}{*}{ AB188301 } & \multirow{2}{*}{55.7} & \multirow{2}{*}{2567} \\
\hline & R-TTAAGTGAAGGCTGTTGTATCATGC & & & \\
\hline \multirow{2}{*}{ TLR5 } & F-TATCAGGATCATGGGAGACT ‘ & \multirow{2}{*}{ FJ754217 } & \multirow{2}{*}{54.7} & \multirow{2}{*}{2581} \\
\hline & R-CTAGGAGATGGTCACGCTT & & & \\
\hline \multirow{2}{*}{ TLR6 } & F-ATGAGCAAAGACAAAGAACCTAC & \multirow{2}{*}{ AB208698 } & \multirow{2}{*}{52.9} & \multirow{2}{*}{2394} \\
\hline & R-TTTTTAAGTTTTCACATCATCCTC & & & \\
\hline \multirow[t]{2}{*}{ TLR7 } & F-TGGTTTTTCCAGTGTGGACG & AB086188.1 & 55.3 & 3191 \\
\hline & R- TCCCCTTGGTTAAGTTAGGC & & & \\
\hline \multirow{2}{*}{ TLR8 } & F-ATGACCCTTCACTT-TTTGCTCCTGACCT & \multirow{2}{*}{ AB092975 } & \multirow{2}{*}{57.8} & \multirow{2}{*}{3113} \\
\hline & R-GAACCACGACCAAACA-TCACCGAGGA & & & \\
\hline \multirow{2}{*}{ TLR9 } & F-GCACCCTGCACCCCCTTTCTCTCCT & \multirow{2}{*}{ АB071394 } & \multirow{2}{*}{63.7} & \multirow{2}{*}{3097} \\
\hline & R-TGGGCTGTCACTCAGTGCTATTCGG & & & \\
\hline \multirow{2}{*}{ TLR10 } & F-CAGAATTACAATGAAACTTATCAGAAGC & \multirow{2}{*}{ AB219565 } & \multirow{2}{*}{53.8} & \multirow{2}{*}{2451} \\
\hline & R-GGGCTTTATAGGCAGTCTGTTTTT & & & \\
\hline
\end{tabular}

Table 1: Sequence of PCR Primers for Cloning of Porcine TLRs.

In gradient PCR cDNA from PAM total RNA served as templates, PCR product from each gene was cloned and two clones per gene were sequenced and registered in GenBank, the accession number of each TLRs are in (Table 2), blast results show a high homology with the sequences released in Gen Bank.

\begin{tabular}{|c|c|c|c|c|c|c|c|c|}
\hline Gene & ID & $\begin{array}{c}\text { Nucleotide Homology } \\
\mathbf{( \% )}\end{array}$ & $\begin{array}{c}\text { (G+C) } \\
\mathbf{\%}\end{array}$ & Amino Homology (\%) & ORF(n) & $\begin{array}{c}\text { Amino } \\
\text { acid (aa) }\end{array}$ & $\begin{array}{c}\text { Predicted } \\
\text { MW (kDa) }\end{array}$ & Leu (\%) \\
\hline TLR1 & KF019632 & 99.43 & 41.5 & 98.62 & 2391 & 796 & 91.1 & 14.32 \\
\hline TLR2 & KF460452 & 99.51 & 46.9 & 99.11 & 2358 & 785 & 89.6 & 15.03 \\
\hline TLR3 & KT735340 & 99.96 & 47.4 & 99.89 & 2717 & 905 & 99.55 & 16.9 \\
\hline TLR4 & KF460453 & 99.53 & 44.5 & 99.29 & 2526 & 841 & 96.3 & 16.05 \\
\hline TLR5 & KF019633 & 99.46 & 48.4 & 99.65 & 2571 & 856 & 92.7 & 18.01 \\
\hline TLR6 & KF019634 & 99.87 & 40.1 & 99.87 & 2391 & 796 & 91.4 & 14.32 \\
\hline TLR7 & KT735339 & 99.81 & 47.7 & 99.52 & 3153 & 1050 & 115.5 & 16.29 \\
\hline TLR8 & KF019635 & 99.42 & 43.2 & 99.32 & 3087 & 1028 & 118.8 & 15.86 \\
\hline TLR9 & KF155478 & 99.58 & 62.8 & 99.51 & 3093 & 1030 & 115.9 & 15.04 \\
\hline
\end{tabular}


Citation: Hong W, Zhang L, Chen P, Dai S, Xia Y, et al. (2018) Staphylococcal Enterotoxins Modulated the Porcine Toll-Like Receptor Transcription and Medicated Inflammatory Response. Arch Vet Sci Technol: AVST-141. DOI: 10.29011/AVST-141. 100041

\begin{tabular}{|l|l|l|l|l|l|l|l|l|}
\hline TLR10 & KF019636 & 99.92 & 39.4 & 99.75 & 2436 & 811 & 94.2 & 18.74 \\
\hline
\end{tabular}

Table 2: Sequence characteristics analysis of porcine TLR1-10.

\section{Bioinformatics Analysis}

Signal P 4.1 Server-prediction and TMHMM Server v2.0 analysis results display that all of these TLRs have signal peptides, extracellular region, transmembrane region and intracellular region (Table 3).

\begin{tabular}{|c|c|c|c|c|c|}
\hline Genes & LRRs Number of LRRs & Signal peptide & Ectodomain & Transmembrane & TIR \\
\hline TLR1 & 7 & $1-26$ & $1-585$ & $586-608$ & $609-796$ \\
\hline TLR2 & 4 & $1-21$ & $1-588$ & $589-611$ & $612-785$ \\
\hline TLR3 & 17 & $1-29$ & $1-728$ & $729-751$ & $778-927$ \\
\hline TLR4 & 13 & $1-23$ & $1-638$ & $639-661$ & $662-841$ \\
\hline TLR5 & 7 & $1-19$ & $1-642$ & $643-665$ & $666-856$ \\
\hline TLR6 & 5 & $1-23$ & $1-586$ & $587-609$ & $610-796$ \\
\hline TLR7 & 15 & $1-27$ & $1-835$ & $844-866$ & $891-1049$ \\
\hline TLR8 & 13 & $1-19$ & $1-814$ & $815-837$ & $838-1028$ \\
\hline TLR9 & 16 & $1-24$ & $1-816$ & $817-835$ & $836-1030$ \\
TLR10 & 5 & $1-19$ & $1-576$ & $577-599$ & $600-811$ \\
\hline
\end{tabular}

Table 3: Structural Features of Porcine TLR Protein.

he simple modular architecture research tool (SMART) was employed to predict the domain structure of porcine TLR1-10, (Figure 1) is the schematic diagram defined by SMART, the result indicates that porcine TLRs consistent of transmembrane domain, TIR domain of the intracellular region and LRR domains of the extracellular region, which is correspond to currently known protein structure characteristics of TLRs family [21,22].



Figure 1: Schematic Diagram Domains Structure of Porcine TLR1-10.

The domain organization of TLRs was predicted by using the SMART program analysis. The GenBank accession numbers of TLR sequences used for comparison are listed in (Table 3). TIR: Toll/IL-1 receptor; TM: transmembrane domain; LRR: Leucinerich repeat; NT: N terminal; CT: C-terminal; Black vertical line marking: Amino acid mutation.

The multiple alignments showed that the numbers of LRR repeats in the 10 TLR's are 8 in TLR1, 7 in TLR2, 18 in TLR3, 14 in
TLR4, 11 in TLR5, 6 in TLR6, 17 in TLR7, 16 in TLR8, 17 in TLR9, 6 in TLR10. Endosomal TLRs have more LRR than cell surface expressed TLRs, and studies also showed that cell surface expressed TLRs tend to be more prone to positive selection than endosomal TLRs $[23,24]$. Pedro J Esteves' study shown that endosomal TLRs and cell surface expressed TLRs display different patterns of molecular evolution due to the different nature of the PAMPs they recognize [23]. TLRs that exist on the cell surface have a more flexible evolution and easily tolerate non-synonymous mutations which, in some circumstances, can be subject to positive selection [25].

Pairwise genetic distances were compared between the LRR domain and the TIR domain of 7 species, indicating the LRR domains evolved significantly more rapidly than did the corresponding TIR domains. The evolutionary rates of the LRR domain also differ considerably among these members of TLRs (Table 4).

\begin{tabular}{|c|c|c|}
\hline \multirow{2}{*}{ TLR Member } & \multicolumn{2}{|c|}{ Pairwise genetic distances } \\
\cline { 2 - 3 } & $\Delta_{\text {TIR-LRR }}$ & $\mathbf{p ~ v a l u e}$ \\
\hline TLR1 & -0.63 & 0.001 \\
\hline TLR2 & -0.08 & 0.001 \\
\hline TLR3 & -0.137 & 0.025 \\
\hline TLR4 & -0.233 & 0.100 \\
\hline TLR5 & -0.133 & 0.012 \\
\hline TLR6 & -0.023 & 0.022 \\
\hline TLR7 & -0.013 & 0.005 \\
\hline TLR8 & -0.067 & 0.034 \\
\hline TLR9 & -0.363 & 0.016 \\
\hline TLR10 & -0.003 & 0.001 \\
\hline
\end{tabular}

Table 4: Average differences in genetic distances, $\Delta_{\text {TIR-LRR }} \Delta_{\text {TIR-LRR }}$ 


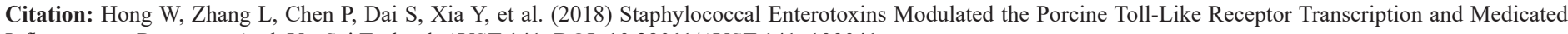
Inflammatory Response. Arch Vet Sci Technol: AVST-141. DOI: 10.29011/AVST-141. 100041

values in TLRs1, 2, 3, 4, 5, 6, 7, 8, 9, 10, $\Delta_{\text {TIR-LRR }} \Delta_{\text {TIR-LRR }}$ is the average of pairwise genetic distances between LRR domain and TIR domain in TLRs.

TLRs 3, 7, 8 and 9 recognize viral nucleic acids, which needs to avoid reaction against self-derived nucleic acids, this delicate trade-off might constrain the evolution of TLR3 and TLR7 [26], although such a point of view does not reasonably explain the faster evolution of the LRR domain in TLR8 and TLR9 [19].

\section{Evolution of Mammalian TLR Gene}

The TLR1-10 amino acid sequences from dog, bovine, pig, man and ovine, and TLR1-9 of mouse, were used to calculate the evolutionary relationships between the TLR genes (Table 5).

\begin{tabular}{|c|c|c|c|c|c|c|}
\hline Gene & $\begin{array}{c}\text { Nonsynonymous- } \\
\text { mutation }\end{array}$ & $\begin{array}{c}\text { Synonymous } \\
\text { mutations }\end{array}$ & $\begin{array}{c}\text { Nucleotide al- } \\
\text { leles }\end{array}$ & \multicolumn{3}{|c|}{ Amino acids } \\
\hline & & & & Alleles & Feature & Nature change \\
\hline \multirow[t]{11}{*}{ TLR1 } & $11(7 / 4)$ & $3(2 / 1)$ & $76 \mathrm{~T} / \mathrm{C}$ & $26 \mathrm{~S} / \mathrm{P}$ & $\mathrm{P} / \mathrm{NP}$ & Hydrophilic / hydrophobic \\
\hline & & & $374 \mathrm{~A} / \mathrm{T}$ & $125 \mathrm{H} / \mathrm{L}$ & $+/ \mathrm{NP}$ & Alkaline / hydrophobic \\
\hline & & & $671 \mathrm{G} / \mathrm{A}$ & $224 \mathrm{~S} / \mathrm{N}$ & $\mathrm{P} / \mathrm{P}$ & - \\
\hline & & & $932 \mathrm{C} / \mathrm{T}$ & $311 \mathrm{~A} / \mathrm{V}$ & NP/NP & - \\
\hline & & & $1036 \mathrm{C} / \mathrm{G}$ & $346 \mathrm{~L} / \mathrm{V}$ & NP/NP & - \\
\hline & & & $1160 \mathrm{G} / \mathrm{A}$ & $387 \mathrm{R} / \mathrm{Q}$ & $+/ \mathrm{P}$ & Alkaline / neutral \\
\hline & & & $1196 \mathrm{~A} / \mathrm{G}$ & $399 \mathrm{~K} / \mathrm{R}$ & $+/+$ & - \\
\hline & & & $1337 \mathrm{G} / \mathrm{A}$ & $446 \mathrm{C} / \mathrm{Y}$ & $\mathrm{P} / \mathrm{P}$ & - \\
\hline & & & $1370 \mathrm{~A} / \mathrm{G}$ & $457 \mathrm{H} / \mathrm{R}$ & $+/+$ & - \\
\hline & & & $1613 \mathrm{G} / \mathrm{A}$ & $538 \mathrm{G} / \mathrm{D}$ & $\mathrm{P} /-$ & Neutral / acidic \\
\hline & & & $1652 \mathrm{C} / \mathrm{T}$ & $551 \mathrm{~A} / \mathrm{V}$ & NP/NP & - \\
\hline TLR2 & $7(2 / 5)$ & $5(1 / 4)$ & $427 \mathrm{G} / \mathrm{A}$ & $143 \mathrm{~A} / \mathrm{T}$ & $\mathrm{NP} / \mathrm{P}$ & Hydrophobic / neutral \\
\hline & & & $490 \mathrm{C} / \mathrm{G}$ & $164 \mathrm{P} / \mathrm{A}$ & NP/NP & - \\
\hline & & & $742 \mathrm{~A} / \mathrm{C}$ & $248 \mathrm{H} / \mathrm{P}$ & $+/ \mathrm{NP}$ & Alkaline / hydrophobic \\
\hline & & & $745 \mathrm{~T} / \mathrm{A}$ & $249 \mathrm{C} / \mathrm{S}$ & $\mathrm{P} / \mathrm{P}$ & - \\
\hline & & & $886 \mathrm{C} / \mathrm{T}$ & $296 \mathrm{~L} / \mathrm{F}$ & NP/NP & - \\
\hline & & & $1853 \mathrm{G} / \mathrm{A}$ & $618 \mathrm{C} / \mathrm{Y}$ & $\mathrm{P} / \mathrm{P}$ & - \\
\hline & & & $2233 \mathrm{~A} / \mathrm{G}$ & $745 \mathrm{~T} / \mathrm{A}$ & $\mathrm{P} / \mathrm{NP}$ & Neutral / hydrophobic \\
\hline TLR4 & $6(3 / 3)$ & $6(4 / 2)$ & $459 \mathrm{~T} / \mathrm{G}$ & $153 \mathrm{~N} / \mathrm{K}$ & $\mathrm{P} /+$ & Neutral / Alkaline \\
\hline & & & $575 \mathrm{~A} / \mathrm{G}$ & $192 \mathrm{H} / \mathrm{R}$ & $+/+$ & - \\
\hline & & & $611 \mathrm{~A} / \mathrm{T}$ & $204 \mathrm{H} / \mathrm{L}$ & $+/ \mathrm{NP}$ & Alkaline / hydrophobic \\
\hline & & & $763 \mathrm{G} / \mathrm{A}$ & $255 \mathrm{~V} / \mathrm{I}$ & NP/NP & - \\
\hline & & & $949 \mathrm{~A} / \mathrm{G}$ & $317 \mathrm{~S} / \mathrm{G}$ & $\mathrm{P} / \mathrm{P}$ & - \\
\hline & & & $962 \mathrm{~A} / \mathrm{G}$ & $321 \mathrm{H} / \mathrm{R}$ & $+/+$ & - \\
\hline TLR5 & $3(2 / 1)$ & $11(0 / 11)$ & $169 \mathrm{~A} / \mathrm{G}$ & $57 \mathrm{I} / \mathrm{V}$ & NP/NP & - \\
\hline & & & $1205 \mathrm{C} / \mathrm{T}$ & $402 \mathrm{P} / \mathrm{L}$ & NP/NP & - \\
\hline & & & $1442 \mathrm{~A} / \mathrm{G}$ & $481 \mathrm{E} / \mathrm{G}$ & $-/ \mathrm{P}$ & Acidic / neutral \\
\hline
\end{tabular}




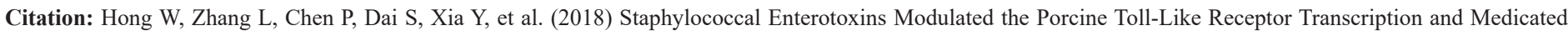
Inflammatory Response. Arch Vet Sci Technol: AVST-141. DOI: 10.29011/AVST-141. 100041

\begin{tabular}{|c|c|c|c|c|c|c|}
\hline TLR6 & $1(0 / 1)$ & $2(1 / 1)$ & $206 \mathrm{~T} / \mathrm{C}$ & $69 \mathrm{~L} / \mathrm{P}$ & $\mathrm{NP} / \mathrm{NP}$ & - \\
\hline \multirow[t]{7}{*}{ TLR8 } & \multirow[t]{7}{*}{$7(5 / 2)$} & \multirow[t]{7}{*}{$11(7 / 4)$} & $140 \mathrm{C} / \mathrm{A}$ & $47 \mathrm{~T} / \mathrm{N}$ & $\mathrm{P} / \mathrm{P}$ & - \\
\hline & & & $334 \mathrm{~A} / \mathrm{C}$ & $178 \mathrm{E} / \mathrm{D}$ & $-/-$ & - \\
\hline & & & $570 \mathrm{~A} / \mathrm{T}$ & $190 \mathrm{~L} / \mathrm{F}$ & $\mathrm{NP} / \mathrm{NP}$ & - \\
\hline & & & $843 \mathrm{~T} / \mathrm{C}$ & $278 \mathrm{~A} / \mathrm{E}$ & $\mathrm{NP} /-$ & Hydrophobic / acidic \\
\hline & & & $963 \mathrm{~T} / \mathrm{A}$ & $321 \mathrm{E} / \mathrm{N}$ & $-/ \mathrm{P}$ & Acidic / neutral \\
\hline & & & $1571 \mathrm{G} / \mathrm{A}$ & $524 \mathrm{C} / \mathrm{Y}$ & $\mathrm{P} / \mathrm{P}$ & - \\
\hline & & & $2342 \mathrm{G} / \mathrm{A}$ & $781 \mathrm{R} / \mathrm{K}$ & $+/+$ & - \\
\hline \multirow[t]{6}{*}{ TLR9 } & \multirow[t]{6}{*}{$6(1 / 5)$} & \multirow[t]{6}{*}{$6(5 / 1)$} & $64 \mathrm{~A} / \mathrm{G}$ & $22 \mathrm{~T} / \mathrm{A}$ & $\mathrm{P} / \mathrm{NP}$ & Neutral/ hydrophobic \\
\hline & & & $325 \mathrm{~T} / \mathrm{C}$ & $109 \mathrm{C} / \mathrm{R}$ & $\mathrm{P} /+$ & Neutral / Alkaline \\
\hline & & & $898 \mathrm{G} / \mathrm{A}$ & $300 \mathrm{~A} / \mathrm{T}$ & $\mathrm{NP} / \mathrm{P}$ & Hydrophobic / neutral \\
\hline & & & $1010 \mathrm{~A} / \mathrm{G}$ & $337 \mathrm{~K} / \mathrm{S}$ & $+/ \mathrm{P}$ & Alkaline / neutral \\
\hline & & & $1011 \mathrm{G} / \mathrm{C}$ & $337 \mathrm{~K} / \mathrm{S}$ & $+/ \mathrm{P}$ & Alkaline / neutral \\
\hline & & & $3044 \mathrm{G} / \mathrm{A}$ & $1015 \mathrm{R} / \mathrm{H}$ & $+/+$ & - \\
\hline TLR10 & $2(1 / 1)$ & 0 & $724 \mathrm{~A} / \mathrm{G}$ & $242 \mathrm{~T} / \mathrm{A}$ & $\mathrm{P} / \mathrm{NP}$ & Neutral / hydrophobic \\
\hline & & & $1648 \mathrm{~T} / \mathrm{C}$ & $550 \mathrm{~S} / \mathrm{P}$ & $\mathrm{P} / \mathrm{NP}$ & Neutral / hydrophobic \\
\hline
\end{tabular}

Table 5: Nonsynonymous Mutations in Eight Porcine TLR Genes.

The split network approach was chosen as the tool to evaluate phylogenetic relationships between TLR gene sequences because it can represent incompatibilities within and between data sets [27]. The inferred TLR phylogenetic network was quite well resolved and tree-like. Results indicate that amino acid homology among porcine TLR1, 2, 4, 5, 6, 8, 9, 10 and cattle TLR1, horse TLR2, cattle TLR4, sheep TLR5, sheep TLR6, cattle TLR8, horse TLR9, cattle TLR10 was 84.42\%, 82.04\%, 80.62\%, 80.77\%, 83.56\%, 79.67\%, 86.23\%, $83.99 \%$ respectively. TLR3 shares a high identity with horse and bovine, among TLRs family, TLR7 is more conserved than others. Porcine TLRs have a high sequence identity(79.67\% 85.05\%) with their cattle counterparts, the next is sheep and horse, $77.26 \% \sim 84.95 \%$ and $74.85 \% \sim 86.23 \%$ respectively, porcine TLRs and human sequence identity is between $98.0 \% \sim 99.6 \%$, porcine TLRs and mouse have the lowest percentage of amino acid homology, between $63.26 \% \sim 74.35 \%$. These results illustrate that TLRs gene appeared to be evolutionarily conserved and possesses species-specificity, TLR9 is the most conserved (sequence identity 86.23\%), whilst TLR4, 5, 8 exhibit high species-specificity (sequence identity 80.62\%, 80.77\%, 79.67\% respectively). Phylogenetic tree was obtained by MEGA7.0, using neighbor-joining method. ITOL is used to prune the tree (http://itol.embl.de/). The inferred TLR phylogenetic tree was showed in (Table 6 and Figure 2). 
Citation: Hong W, Zhang L, Chen P, Dai S, Xia Y, et al. (2018) Staphylococcal Enterotoxins Modulated the Porcine Toll-Like Receptor Transcription and Medicated Inflammatory Response. Arch Vet Sci Technol: AVST-141. DOI: 10.29011/AVST-141. 100041

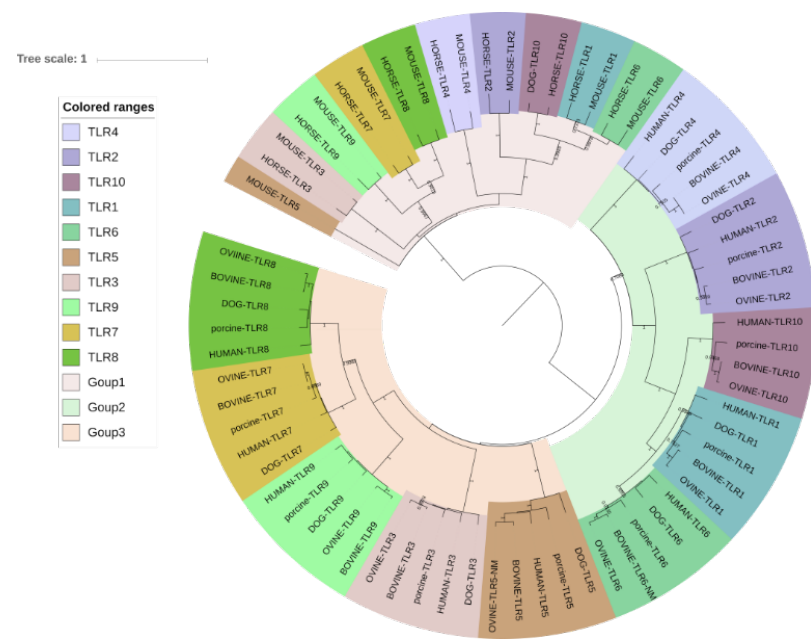

Figure 2: Phylogenetic Tree of Mammalian TLRs Based On 69 Amino Acid Sequences of TLR1-10 From Sheep, Cow, Pig, Man, Dog and Mouse.

The edges are labeled with the percent bootstrap support attained in 1000 bootstrap replicates. The upper scale measures genetic distance in substitutions per amino acid.

\begin{tabular}{|c|c|c|c|c|c|c|c|}
\hline Genes & Pig (\%) & Bovine (\%) & Ovine (\%) & Horse (\%) & Human (\%) & $\operatorname{Dog}(\%)$ & Mouse (\%) \\
\hline TLR1 & 100 & 84.42 & 77.26 & 79.65 & 77.51 & 80.15 & 72.36 \\
\hline TLR2 & 100 & 81.27 & 80.51 & 82.04 & 78.47 & 77.32 & 68.54 \\
\hline TLR3 & 100 & 86.41 & 85.75 & 87.40 & 83.54 & 85.08 & 77.46 \\
\hline TLR4 & 100 & 80.62 & 79.67 & 74.85 & 72.77 & 74.20 & 63.26 \\
\hline TLR5 & 100 & 79.72 & 80.77 & - & 77.27 & 69.20 & 69.27 \\
\hline TLR6 & 100 & 83.44 & 83.56 & 79.40 & 79.50 & 72.38 & 70.14 \\
\hline TLR7 & 100 & 90.67 & 90.86 & 87.05 & 84.48 & 87.24 & 77.90 \\
\hline TLR8 & 100 & 79.67 & 78.51 & 78.90 & 73.20 & - & 69.82 \\
\hline TLR9 & 100 & 85.05 & 84.95 & 86.23 & 81.22 & 85.58 & 74.35 \\
\hline TLR10 & 100 & 83.99 & 80.30 & - & 80.27 & 82.61 & - \\
\hline
\end{tabular}

Table 6: Overall Amino Acid Similarity of Porcine TLRs To Bovine, Sheep, Horse, Human and Mouse, Dog Expressed as A Percentage.

These TLR molecules were classified into 4 groups, including TLR2 family (TLR1, 2, 6, 10), TLR9 family (TLR7, 8, 9), TLR4, TLR3, TLR5 by phylogenetic tree analysis. The same type of TLR in different mammals shares a same clade, indicating that the difference of TLR subtype is greater than that among species. TLR 1, 6, 10 belong toTLR2 subfamily, TLR 3, 7, 8, 9 are in the same subgroup, TLR 4 and TLR 5 are clustered separately in a sub group under the main mammal's cluster.

\section{Homology Modeling of Porcine Toll-Like Receptors 1-10}

Homology modeling is an effective tool to predict protein tertiary structure since the lack of determined crystal structure, in order to obtain 3D-structure of porcine TLRs, we used MODELLER9.16 coordinate the models, SAVES and Verify_3D was chosen to evaluate our models, Chiron was applied to optimize the models. To predict the possible binding pockets, Pocket-Finder was used to determine putative binding sites for ligands.

The result suggested that the same TLRs from different mammalians can be classified into a group since their high degree of similarity; illustrating TLRs subtype's differences are more remarkable than evolutionary diversities between species. The TLR2 subfamily is composed of TLR1, 2, 6, 10 as their close evolutionary relationships. TLR 8 and TLR9 consist of TLR9 subfamily. Whilst the major TLR gene sub-families and the singletons TLR3, TLR4 and TLR5 were well supported by the bootstrap value. TLR1 and TLR6 


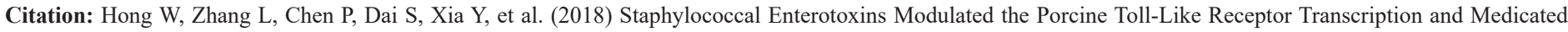
Inflammatory Response. Arch Vet Sci Technol: AVST-141. DOI: 10.29011/AVST-141. 100041

sequences proved to be parallel edges, instead of single branches. This may reflect the high homology between the TLR1 and TLR6 genes between different species.

The Extracellular Domains (ECD) of TLRs in complex with their ligands take the form of M-shaped, which is composed of a large semicircular N-terminal LRR domain and a smaller ellipsoidal Cterminal LRR domain, the N-terminal including an irregular capping region, a central $\beta$-sheet constituted by parallel $\beta$-strands provided by the LxxLxLxxN motifs to form the concave of the horseshoeshaped ectodomain [5], the concave part of the structure contains the central $\beta$ sheet, and the convex part consists of parallel loops and short $3_{10}$ helices, random coils and other structures make up about 60 percent of TLRs overall structure. The dimeric crystal structure of TLR1-TLR2, TLR2-TLR6, and TLR2-TLR10 is quite similar, suggesting that they have a high evolutionary conservation [28].

\section{Cell Membrane Surface TLRs}

TLR1, 2, 4, 5, 6 and 10, are located at the cell surface. TLR2 recognize an extensive range of ligands because of its collaboration with other TLRs such as TLR1and TLR6 [29,30]. TLR2 can recognize abundant ligands due to its modulation of heterodimeric partners, the TLR2-TLR6 complex has binding sites of diacyl lipopeptides, whereas if its cooperator change to TLR1, TLR1-TLR2 complex can bind to triacyl lipopeptides, homodimerization of TLR2 also can recruit ligands to active the signaling without TLR 1 or TLR6 [31,32]. Homology model of TLR10 is similar to TLR2 [33].

In TLR1-TLR2 and TLR2-TLR6 complex, TLR2 is essential for the interaction with ligands, its lipid chains with carbons make it have a strong binding affinity to diverse ligands, in TLR2, structural changes of branched carbons and double bonds have little interference with glycolipids interaction [34,35].

The arrangement of hydrogen bonds between glycerol and the peptide backbone of the lipopeptides and the LRR loops of the TLRs is a key factor of TLR heterodimerization. These hydrogen bonds play a role as a bridge between TLR 2 and TLR $1 / 6$, and they also important for the stabilization of hydrophobic pocket of dimerization interface. The amide-bound lipid chain with at least 8 carbons inserts into TLR2 hydrophobic pocket, facilitating TLR1TLR2 heterodimerization. The N-terminal cysteine have an auxiliary role in TLR2 ligands binding and dimerization, the N-terminal cysteine is combined with lipid chains by the covalent bonds and the sulfur side chain interacts with hydrophobic pocket of TLR2, these bring the result of absolutely conserved N-terminal cysteine.

TLR2 is common activated by a wide variety of microbial products apart from lipoproteins, including lipoteichoic acids, lipomannans, peptidoglycans, zymosans, phenol soluble modules, and hyaluronans. The model shows that the overall shape of the complex is resemblance to the letter M: The two N-terminal domains stretch outward at opposite ends and the $\mathrm{C}$-terminal domains converge in the middle (Figure 3).
The extracellular domain of TLR4 forms homo-dimer which recognizes LPS produced by gram negative bacteria [36], this function requires its co-receptor: myeloid differentiation-2(MD-2), a secreted soluble glycoprotein protein. As other TLRs, TLR4 homodimer is horseshoe-like shaped, MD-2 can bind to (about a third of MD-2 but not the entirety) the concave surface of the complex, other parts can bond to LPS. The interaction between TLR4 and MD-2 is stable because it is mainly H-bond and Coulombic forceterminal domain of TLR4 is negatively charged, while residues from the central domain are mainly positively charged. PS binds to the hydrophobic pocket of MD-2, and the MD-2-LPS complex is a bridge between TLR4 homodimer by binding two different interfaces. TLR4-MD-2 dimerizes under the facilitating of lipid chains and the phosphate domains, the lipid chains of LPS insert into the hydrophobic pocket of MD-2, LPS interact with TLR4 simultaneously-terminal domain of TLR4 binds to hydrophobic residues of MD-2 [37,38]. Research shows that five lipid chains of LPS binds to MD-2 and the six-lipid chain interacts with a hydrophobic pocket of TLR4, extra chains can become obstacles between TLR4 and MD-2 in consideration of steric hindrance. For the same reason, the space volume of MD-2 pocket is limited; more lipid chains will reduce the form of TLR4 dimerization (Figure 3d).

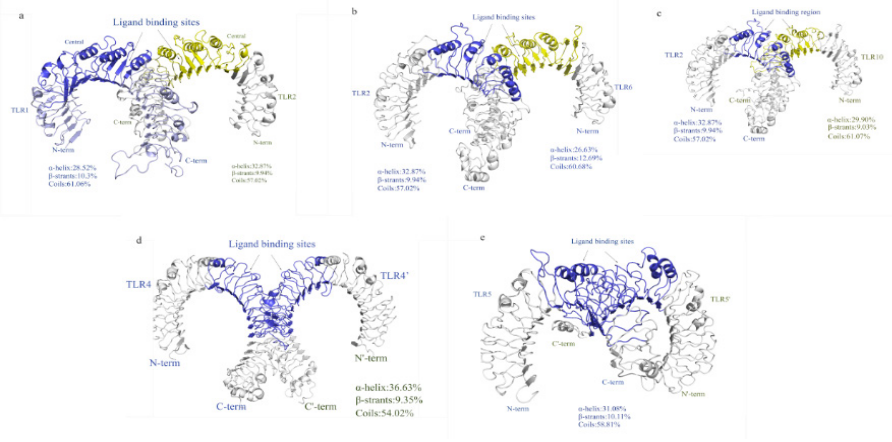

Figures 3(a-e): Structural models and ligand-binding regions of TLR2TLR1/6/10 heterodimers and homodimers of TLR4/5. (a, b, c) TLR2TLR1/6/10 heterodimers, the ligand-binding regions are colored light blue, light yellow. (d, e) TLR4, TLR5 homodimers, ligand-binding regions are colored light blue.

TLR5 binds to protein and bacterial flagella, initiating a signaling cascade such as MyD88-dependent signaling and NF-kB, which leads innate immune system to against flagellated bacteria [39].TLR5 LRR domain composes by an $N$-terminal $\beta$-hairpin capping motif, 13 complete LRR modules (LRR13), and two residues from LRR14.The concave surface of horseshoe-like shape is a $\beta$-sheet structure, which is built by two anti-parallel $\beta$-strands of $N$-terminal $\beta$-hairpin capping motif and 13 parallel $\beta$-strands of LRR modules, other parts of the concave surface is irregular helices and extended structures (Figure 3e).

\section{Endosomal TLRs}

TLR3, 7, 8 and 9, are located primarily within the cytoplasm 


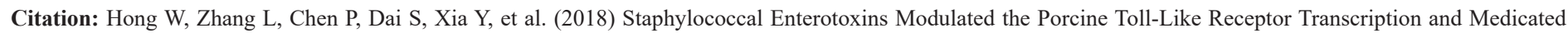
Inflammatory Response. Arch Vet Sci Technol: AVST-141. DOI: 10.29011/AVST-141. 100041

whereas the bacterial and fungal sensors. Positive stranded RNA virus produces double stranded RNA (dsRNA) during their replication, TLR3 is responsible for recognizing these exogenous dsRNAs [39]. The length of exogenous RNA is minimum restricted for binding to N-terminal and C-terminal LRRs of TLR3.The overall structure of dsRNAs-induced TLR3 homodimer is similar to letter $\mathrm{M}$, although resembles TLR2-TLR4/6 complex, ligand-identification mechanism is absolutely different. The dsRNA ligand has two binding sites on TLR3, the N-terminal LRR and the C-terminal $\mathrm{LRR}$, the distance between two binding sites is roughly four times of helical turns of RNA, a probable explanation of RNA length dependency in binding. Phosphate backbones of the dsRNA interact with cationic residues of both termini of TLR3 [40], TLR3ECD surface proximal to the $\mathrm{C}$-terminus also contains positively charged residues, which is another binding site of dsRNA ligands, these two sites make TLR3 could bond two flanks of dsRNA. Notably, there is a potential binding site on the concave surface of TLR3-ECD, but glycosylation may hinder dsRNA binding, TLR3 could regulate dsRNA binding whereby glycosylating (Figure 4).
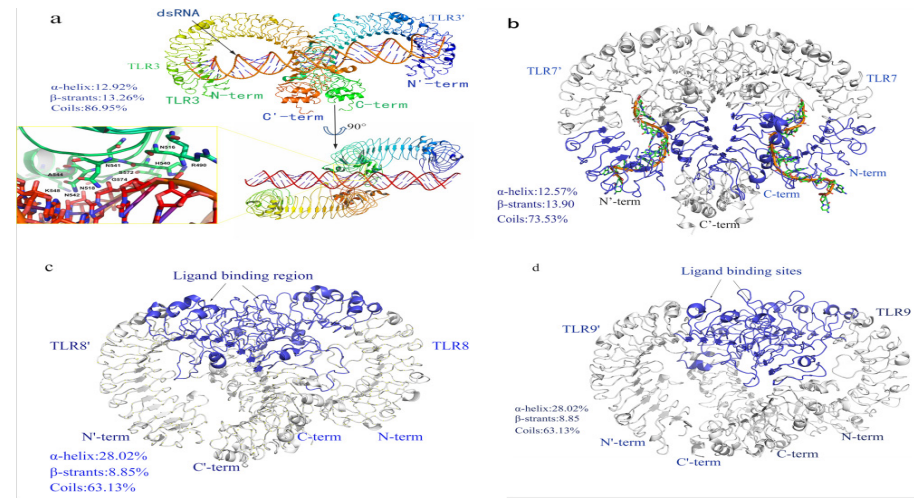

Figure 4: Structure of endosomal TLRs. (a) TLR3-TLR3-dsRNA complex, TLR3 is colored rainbow and dsRNA is colored sepia, possible residues involved in the interaction are shown. (b) TLR7-TLR7 homodimer, ligand-binding regions are colored light blue, possible $\mathrm{CpG}$ binding sites are shown, CpG DNA interacts with the insertion surface of the horseshoe-like shape. (c,d) TLR8/9 homodimer, ligand-binding regions are colored light blue.

TLR7, 8, 9 are the family of nucleic acids sensor, which is expressed in ER and transport to endosomes, TLRs7, 8, and 9 are intracellular organelles TLRs and recognize a wide range of microbial nucleic acids, specifically, TLR7, 8 recognize viral single stranded RNA (ssRNA), while TLR9 is responsible for bacterial DNA [41]. This family members contain a long insertion (coined the "Z-loop") between two of the central LRRs (LRR14 and 15). The Asp residue of TLR7 family (TLR7, 8, 9) is highly conserved, indicating the Asp residue has more pronounced function for TLR7 family. TLR7, 8, 9 have a ligand-binding region located spatially around the Asp residue. In all TLR7, 8, 9 homodimer models, the ssRNA or CpG DNA interacts with the insertion surface of the horseshoe-like shape. (Figure 4) shows the homo-dimer of TLR1TLR7 and TLR8-TLR8 [42].

\section{Transcription Changes of TLRs and Cytokines in PAM Cells Treated by Staphylococcus Enterotoxin}

To explore the immune role of TLRs and cytokines during pathogen invasion, transcript expression changes of each of the TLRs and cytokines was confirmed in PAMs challenged with three Staphylococcal Enterotoxins (rSEO, rSEK, SEA) $(100 \mathrm{ng} / \mathrm{mL})$ by real-time PCR. The results indicate that extracellular TLR1/2/6/10 were indicative of a heightened ability to respond to staphylococcal enterotoxins, while endosomal TLRs(TLR3/7/8/9), TLR4 andTLR5 were no significantly difference or slightly suppressed $(\mathrm{p}<0.05)$ on PAM cells of staphylococcal enterotoxins stimulation (Figure 5A).
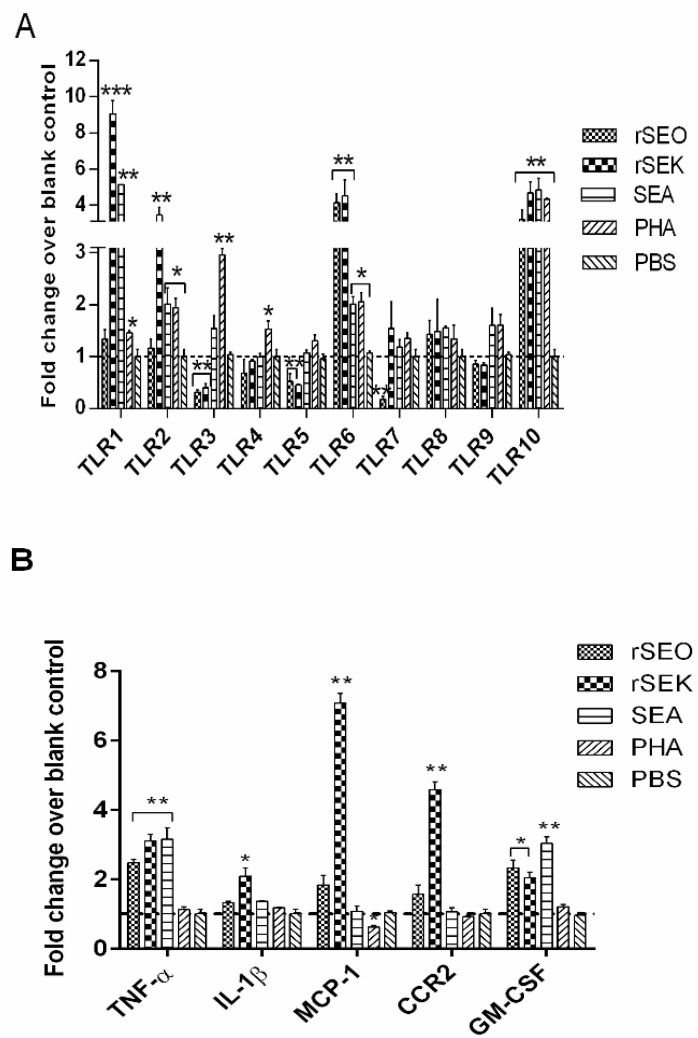

Figures 5(A-B): The TLRs (A) and cytokines (B) transcription ratio of different SE-stimulated PAMs in vitro. 100ng/mL SE-simulated (rSEO, rSEK, SEA) PAMs were incubated for $48 \mathrm{~h}$, quantitative real time PCR (qPCR) assays confirmed expression of TLR1-10 and all cytokines. The GAPDH served as an internal control. Data shown is an average of $n=3$ biological replicates \pm standard error. Error bars represented the standard deviations.

It can be seen from the (Figure 5B), the transcription of GM-CSF and TNF- $\alpha$ was up-regulated in all enterotoxin treatment cells. The transcription levels of chemokine receptor CCR2 and inflammatory cytokines MCP-1 and IL- $1 \beta$ were upregulated in the rSEK treatment cells. The result showed that staphylococcal enterotoxins facilitated the expression of inflammatory cytokines 
Citation: Hong W, Zhang L, Chen P, Dai S, Xia Y, et al. (2018) Staphylococcal Enterotoxins Modulated the Porcine Toll-Like Receptor Transcription and Medicated Inflammatory Response. Arch Vet Sci Technol: AVST-141. DOI: 10.29011/AVST-141. 100041

and chemokine receptor on PAM cells.

\section{TLRs and Cytokines Transcription Change in PBMCs of Staphylococcus Enterotoxin Inoculated Pigs}

In the lack of validated antibodies against the porcine TLRs and cytokines, the quantitative real-time PCR was used to measure TLR and cytokines expression on the PBMCs isolated from pigs inoculated the staphylococcal enterotoxins. Expression of TLR and cytokine genes was normalized against GAPDH, which served as the control. Compared to non-inoculated control, the transcription level of TLR1, 2, 6, 7, 10 were significantly upregulated (4 to 9-fold) in staphylococcal enterotoxin inoculated pigs, endosomal TLRs (TLR3, 8, 9), membrane surface TLR4, 5 were only slightly rising (1-2 fold) post-inoculated from $24 \mathrm{~h}$ to $72 \mathrm{~h}$. Curiously, endosomal TLR7 mRNA transcription in PBMCs have a 2 to 4 -fold up-regulation. The transcription level of other membrane surface TLRs (TLR1, $2,6,10$ ) were upregulated significantly in rSEO inoculation pigs, especially TLR6, indicating that rSEO activates innate immunity by a TLR-dependent way, and TLR 1, 2, 6, and 10 may play a crucial role on recognizing and signal transduction to the staphylococcal enterotoxin super antigen stimulation (Figure 6A).

On the whole, the transcription level of several inflammatory cytokines was elevated at a certain point in time, indicating that enterotoxin rSEO can promote transcription of inflammatory cytokines in peripheral blood lymphocytes. As shown in (Figure 6B).

A

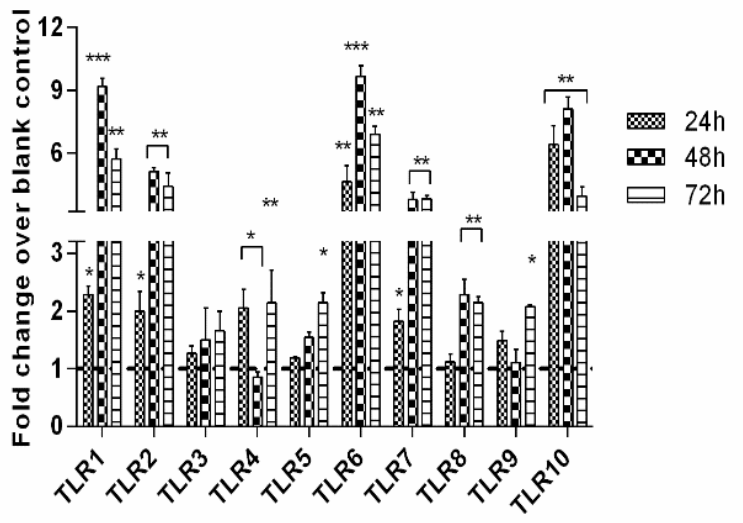

B



Figures 6(A-B): Fold Change of Porcine TLRs (A) and Cytokines (B) Transcription over time in vivo.

Relative transcript abundance of TLRs 1-10 and five cytokines, GM-CSF, IL-1 $\beta$, TNF- $\alpha$, MCP-1 and CCR2 determined staphylococcus enterotoxin injection pigs PBMC cell lines. $100 \mu \mathrm{g}$ staphylococcus enterotoxin was injected into 30-day heath pig, isolated PBMC cells at $0 \mathrm{~h}, 24 \mathrm{~h}, 48 \mathrm{~h}, 72 \mathrm{~h}$, quantitative real time PCR (qPCR) assays confirmed expression of TLR1-10 and all cytokines. The GAPDH served as an internal control. Data shown is an average of $n=3$ biological replicates \pm standard error. Error bars represented the standard deviations (Table 7).

\begin{tabular}{|c|c|c|c|c|}
\hline Gene & Primer Sequence (5'-3') & Accession No. & $\operatorname{Tm}\left({ }^{\circ} \mathrm{C}\right)$ & Product (bp) \\
\hline \multirow{2}{*}{ TLR1 } & F-TGTTTTCAAATTCAACCAG & $\mathrm{AB} 086376$ & 47.6 & 75 \\
\hline & R-GGGTGGCACGAAAT & & & \\
\hline \multirow{2}{*}{ TLR2 } & F-CTTCTCCCACTTCCGTCT & NM213761 & \multirow{2}{*}{53.2} & \multirow{2}{*}{127} \\
\hline & R-GGTCCTGGTGTTCATTATCTT & & & \\
\hline \multirow{2}{*}{ TLR3 } & F-CTTTTCCTTTCAATGGCTAA & AB258451 & \multirow{2}{*}{49.1} & \multirow{2}{*}{183} \\
\hline & R-AGAGGAGAATCAGCGAGTG & & & \\
\hline \multirow{2}{*}{ TLR4 } & F-GACGCCTTTGTTATCTACT & $\mathrm{AB} 188301$ & \multirow{2}{*}{52.5} & \multirow{2}{*}{242} \\
\hline & R-TGGGCAATCTCATACTCA & & & \\
\hline
\end{tabular}


Citation: Hong W, Zhang L, Chen P, Dai S, Xia Y, et al. (2018) Staphylococcal Enterotoxins Modulated the Porcine Toll-Like Receptor Transcription and Medicated Inflammatory Response. Arch Vet Sci Technol: AVST-141. DOI: 10.29011/AVST-141. 100041

\begin{tabular}{|c|c|c|c|c|}
\hline \multirow{2}{*}{ TLR5 } & F-GCCTTCAACAAGATAAACA & FJ754217 & \multirow{2}{*}{49.8} & \multirow{2}{*}{275} \\
\hline & R-CCCAAGAAGAGAGTAGGTATG & & & \\
\hline \multirow{2}{*}{ TLR6 } & F-CCTCAAGCATTTGGACCT & AB208698 & \multirow{2}{*}{51.1} & \multirow{2}{*}{313} \\
\hline & R-AGCCAGTTGTAAACACCCTA & & & \\
\hline \multirow{2}{*}{ TLR7 } & F-AAGTGGAAATTGCCCTCGTT & DQ647699 & \multirow{2}{*}{52.8} & \multirow{2}{*}{373} \\
\hline & R-ATAGCCTTTGATCCGCAACA & & & \\
\hline \multirow{2}{*}{ TLR8 } & F-GCTGCCGTTGTTAGAAGT & AB092975 & \multirow{2}{*}{52.0} & \multirow{2}{*}{406} \\
\hline & R-CGGAAACTGCTGGAGTAATG & & & \\
\hline \multirow{2}{*}{ TLR9 } & F-TTCACCTTGGACCTGTCT & AB071394 & \multirow{2}{*}{57.7} & \multirow{2}{*}{451} \\
\hline & R-GGAAGAAGCGGAGATAGAG & & & \\
\hline \multirow{2}{*}{ TLR10 } & F-GATCTGCCCTGGTATCTCA & AB219565 & \multirow{2}{*}{52.4} & \multirow{2}{*}{491} \\
\hline & R-CAACATTTACGCCTATCCT & & & \\
\hline \multirow{2}{*}{ IL-1 $\beta$} & F-TGTTCTGCATGAGCTTTGTG & M86725 & \multirow{2}{*}{55} & \multirow{2}{*}{358} \\
\hline & R-TCTGGGTATGGCTTTCCTTAG & & & \\
\hline \multirow{2}{*}{ MCP-1 } & F-CTCCTGTGCCTGCTGCT & X79416 & \multirow{2}{*}{55} & \multirow{2}{*}{282} \\
\hline & R-TTCAAGGCTTCGGAGTTT & & & \\
\hline \multirow{2}{*}{ GM-CSF } & F-AGCCCTGAGCCTTCTAAAC & AY116504 & \multirow{2}{*}{55} & \multirow{2}{*}{300} \\
\hline & R-CAGTCAAAGGGGATGGTAA & & & \\
\hline \multirow{2}{*}{ TNF- $\alpha$} & F-CGTTGTAGCACAATGTCAAAGCC & X57321 & \multirow{2}{*}{60} & \multirow{2}{*}{402} \\
\hline & R-TTGCCCAGATTCAGCAAAGTCCA & & & \\
\hline \multirow{2}{*}{ CCR2 } & F- AACATTCTGGTTACGCCTGT & AB119271 & \multirow{2}{*}{52.7} & \multirow{2}{*}{124} \\
\hline & R-ATTCCCGAGTAGCAGACG & & & \\
\hline \multirow{2}{*}{ GAPDH } & F-ATGACAACTTCGGCATCGT & AF017079 & \multirow{2}{*}{57.3} & \\
\hline & R-CCAGTGAGCTTCCCGTTGAG & & & 190 \\
\hline
\end{tabular}

Table 7: Primers of Relative FQ-PCR for Detecting TLR1-10, and Immune Related Inflammatory Cytokines.

The transcription of chemokine receptor CCR2 is upregulated at PI $24 \mathrm{~h}$, while other cytokines (TNF- $\alpha$, IL-1 $\beta$ ) transcription levels increased to varying degrees post-inoculation $48 \mathrm{~h}$ or $72 \mathrm{~h}$. The transcription of GM-CSF, and MCP-1 gradually increased with time and reached the peak at PI $72 \mathrm{~h}$. The results hints that the staphylococcal enterotoxin promoted the inflammatory cytokine expression and upregulated chemokine receptor CCR2 expression on PBMCs at early stage of stimulation.

\section{Discussion}

Toll-Like Receptors (TLRs) are type I transmembrane glycoproteins that recognize pathogenic microorganism by ligand binding, arouse robust innate immune response. The recognition of Pathogen-Associated Molecular Patterns (PAMP) [43], such as nucleic acids and structural components of viruses or bacteria is the foundation of this activation. A comparative study with other population, we use SMART and LRR finder to predict the secondary structure of cloned porcine TLR1-10, result shows that the extracellular region these TLRs contains 4-25 Leucine-Rich Repeat (LRR) domains, which plays a crucial role for the recognition of PAMP; transmembrane domain is the anchor of TLRs; cytoplasmic Toll/Interleukin (IL)-1 Receptor (TIR) domain for the activation of downstream signaling cascade. According to the phylogenetic tree, porcine TLRs are highly conserved in comparison with the pig and human genes, having $79-91 \%$ and $73-86 \%$ homology, respectively. TLRs also exhibit a high identity between the same species and different species but the same TLR family members [44].

Sequence analysis suggests that porcine TLR7 is the most conserved gene in these mammals (80-98\% identity), whilst TLR2 and TLR4 are the most diversity, this is a consensus result with David M. Haig's found in sheep [45]. the latent reason probably relates to TLR2 and TLR4 have extreme ability of identifying diversified array of pathogenic ligands, with their co-receptors such as TLR6, MD-2, TLR2 and TLR4 can also have the capacity to recognize products of virus, while TLR7 is responsible for detecting single-stranded viral 



Inflammatory Response. Arch Vet Sci Technol: AVST-141. DOI: 10.29011/AVST-141. 100041

RNA that may more conserved in structure. The "All-round" ability of TLR2 and TLR4 may compel them to be more diversity to reply positive selection from changing pathogen challenge, but on the other hand, the diverse ligands may expect to conserve the interacting sites on TLR2 and TLR4, and this is contradictory [46].

Homologous modeling of porcine TLRs is based on the foregone crystal structure of human TLRs, via using SAVES and Verify_3D to evaluate our models, Chiron was chosen to optimize the models. Results show all of porcine TLRs recognize ligands by forming homodimer or heterodimer, their dimers demonstrate a horseshoe-like shape, composed of $3_{10}$ helices and $\beta$-strands. The asparagine's in the concave surface (also be defined as asparagine ladder) play a role of support of the horseshoe-like shape. Threonine, serine, and cysteine, which can donate hydrogens can be the substitution of asparagine.

As their other mammalian counterparts, the structure of porcine TLRs ectodomain can be classified into two types: TLR3, $5,7,8,9$ own complete asparagine ladders, they were defined as single domain structure TLRs. However, in the case of TLR1, 2, $4,6,10$, their asparagine ladder was substituted with other amino acids, dividing the ectodomain into three regions: $\mathrm{N}$-terminal and $\mathrm{C}$-terminal and central region with discontinuous asparagine ladder (three-domain TLRs). Hydrophilic nucleic acids or proteins mainly bind to TLRs with complete asparagine ladders, the structure of three-domain TLRs a large hydrophobic pocket between the central and the C-terminal, this maybe the reason of three-domain TLRs prefer to bind hydrophobic ligands.

Staphylococcus enterotoxin is a common etiologic agent of possesses numerous virulence factors that manipulate host immunity through TLRs depended way. Toll-like receptor 2 is one receptor in mice implicated in staphylococcus enterotoxin recognition [47]. Toll-like receptor 2 mRNA expression was significantly increased after treatment with SEO in vivo. TLR1/6/10 has the same trends as TLR2 did in vivo and in vitro, suggesting that not only TLR2, and other TLRs in pigs might be participated in the recognition of staphylococcus enterotoxins. Differences in relative abundance may correlate to the sensitivity with which each TLR recognizes staphylococcus enterotoxin. In vitro experiments, when PAMs were deal with three staphylococcus enterotoxins, the relative expression level of TLRs were different between cell surface TLRs and endosomal TLRs, these individual differences in TLR expression may reflect differences in the pathogen challenge experienced by different TLRs. To date, Transcripts from all 10 TLR genes have been identified in only 4 mammalian species, human being, mouse, cow and pig. This report is the first study to conduct thorough sequence analysis of TLR transcripts from pig.

Although a recent study from our laboratory had examined that staphylococcal enterotoxins can promote cytokines secretion, including IL-2, IL-4, IL-6, TNF- $\alpha$ and IFN- $\gamma$ in mice [48]. These our data indicate that that the expression levels of inflammatory cytokines TNF $\alpha, \mathrm{IL}-1 \beta, \mathrm{MCP}-1$ and chemokine receptor CCR2 in PAM cells were upregulated. at varying degrees after different SEs stimulated. The transcription level of GM-CSF, and inflammatory cytokine MCP-1 in PBMCs were significantly up-regulated after SE inoculation, which was involved in the super-antigenicity of staphylococcal enterotoxins. TNF- $\alpha$ increased even more than other cytokines. rSEK stimulation levels are generally higher than other enterotoxins. MCP-1 is mainly recruitment of monocytes, MCP-1 and its receptor CCR2 transcript levels were increased after SEs- stimulated at $72 \mathrm{~h}$, indicating that the secretion of MCP-1 was positively correlated with the efficiency of monocyte-derived mononuclear cells.

In conclusion, we cloned full-length cDNA sequence of porcine TLRs, sequence alignment showed that porcine TLR sequences share high similarity to bovine, mouse and human genes. As the lack of crystal structures for most TLR ligand-binding ectodomains, homology modeling on the basis of the determined crystal structures of TLR ectodomain extends the study of structure and gives us insight into the way of understanding TLR signaling pathways and their effect on innate immunity. Real time PCR assays were developed for each of the TLRs and these were used to quantify expression within staphylococcus enterotoxin. Our study suggesting that not only TLR2, and other TLRs (TLR1, 6, 10) in pigs might be participated in the recognition of staphylococcus enterotoxins which caused by infection of proinflammatory cytokines IL$1 \beta, \mathrm{TNF}-\alpha$ are the first to be activated, as the continued recruitment of immune cells, GM-CSF stimulated granulocyte activation, and finally activation of $\mathrm{T}$ cell proliferation, produce large amounts of inflammatory cytokines, formed inflammation storm. Assays such as these will be vital to improving our understanding of the early events controlling immunological development in porcine.

\section{Acknowledgments}

This work was supported by the National Key Research Project of China (2016YFD050030). National Natural Science Foundation of China (31272540) and the underprop project of Tianjin Science and Technology Committee in China (16YFZCNC00640 and 17JCZDJC33900).

\section{Declaration of Conflicting Interests}

The author (s) declared no potential conflicts of interest with respect to the research, authorship, and/or publication of this article. This manuscript does not contain any individual personal data, and individual consent to publish is not applicable.

\section{Author Contributions}

Conceived and designed the experiments: Jinhai Huang. Performed the experiments: Wenjiao Hong, Lilin Zhang, Songbao Dai, Yihe Xia, Pei Chen and Lei Zhang. Analyzed the data: Songbao Dai and Lei Zhang. Contributed reagents/materials /analysis tools: Jinhai Huang. Wrote the paper: Wenjiao Hong and Jinhai 
Citation: Hong W, Zhang L, Chen P, Dai S, Xia Y, et al. (2018) Staphylococcal Enterotoxins Modulated the Porcine Toll-Like Receptor Transcription and Medicated Inflammatory Response. Arch Vet Sci Technol: AVST-141. DOI: 10.29011/AVST-141. 100041

Huang.

\section{References}

1. Hurst J, Von Landenberg P (2008) Toll-like receptors and autoimmunity. Autoimmunity reviews 7: 204-208.

2. Lopes JA, Borges-Canha M, Pimentel-Nunes P (2016) Innate immunity and hepatocarcinoma: Can toll-like receptors open the door to oncogenesis? World journal of hepatology 8: 162-182.

3. Jin MS, Lee JO (2008b) Structures of TLR-ligand complexes. Curr Opin Immunol 20: 414-419.

4. Fink IR, Pietretti D, Voogdt CG, Westphal AH, Savelkoul HF, et al. (2016) Molecular and functional characterization of Toll-like receptor (TIr)1 and TIr2 in common carp (Cyprinus carpio). Fish Shellfish Immunol 56: 70-83.

5. Parthier C, Stelter M, Ursel C, Fandrich U, Lilie H, et al. (2014) Structure of the Toll-Spatzle complex, a molecular hub in Drosophila development and innate immunity. Proceedings of the National Academy of Sciences of the United States of America 111: 6281-6286.

6. Carpenter S, O'Neill LA (2007) How important are Toll-like receptors for antimicrobial responses? Cellular microbiology 9: 1891-1901.

7. Fraser IP, Stuart L, Ezekowitz RA (2004) TLR-independent pattern recognition receptors and anti-inflammatory mechanisms. J Endotoxin Res 10: 120-124.

8. Kang JY, Lee JO (2011) Structural biology of the Toll-like receptor family. Annual review of biochemistry 80: 917-941.

9. Kumar H, Kawai T, Akira S (2009) Toll-like receptors and innate immunity. Biochem Biophys Res Commun 388: 621-625.

10. Chang ZL (2010) Important aspects of Toll-like receptors, ligands and their signaling pathways. Inflamm Res 59: 791-808.

11. Kawai T, Akira S (2011) Toll-like receptors and their crosstalk with other innate receptors in infection and immunity. Immunity 34: 637-650.

12. Roach JC, Glusman G, Rowen L, Kaur A, Purcell MK, et al. (2005) The evolution of vertebrate Toll-like receptors. Proc Natl Acad Sci USA 102: 9577-9582.

13. Temperley ND, Berlin S, Paton IR, Griffin DK, Burt DW (2008) Evolution of the chicken Toll-like receptor gene family: a story of gene gain and gene loss. BMC Genomics 9: 62.

14. Matsushima N, Tanaka T, Enkhbayar P, Mikami T, Taga M, et al. (2007) Comparative sequence analysis of Leucine-Rich Repeats (LRRs) within vertebrate toll-like receptors. BMC Genomics 8: 124.

15. Honegr J, Soukup O, Dolezal R, Malinak D, Penhaker M, et al. (2015) Structural Properties of Potential Synthetic Vaccine Adjuvants - TLR Agonists. Curr Med Chem 22: 3306-3325

16. Reuven EM, Fink A, Shai Y (2014) Regulation of innate immune responses by transmembrane interactions: lessons from the TLR family. Biochim Biophys Acta 1838: 1586-1593.

17. Deng S, Zhu S, Qiao Y, Liu YJ, Chen W, et al. (2014) Recent advances in the role of toll-like receptors and TLR agonists in immunotherapy for human glioma. Protein \& cell 5: 899-911.

18. Hritz I, Mandrekar P, Velayudham A, Catalano D, Dolganiuc A, et al (2008) The critical role of Toll-Like Receptor (TLR) 4 in alcoholic liver disease is independent of the common TLR adapter MyD88. Hepatology 48: 1224-1231.

19. Mikami T, Miyashita H, Takatsuka S, Kuroki Y, Matsushima N (2012) Molecular evolution of vertebrate Toll-like receptors: evolutionary rate difference between their leucine-rich repeats and their TIR domains. Gene 503: 235-243.

20. Li Y, Deng H, Shi PD, Xu DD, Zhang LL, et al. (2017a) Toxic effects of seu are different from those of other staphylococcal enterotoxins. Am J Transl Res 9: 1618-1629.

21. Jin MS, Lee JO (2008a) Structures of the toll-like receptor family and its ligand complexes. Immunity 29: 182-191.

22. Takeda K, Akira S (2005) Toll-like receptors in innate immunity. International immunology 17: 1-14

23. Areal H, Abrantes J, Esteves PJ (2011) Signatures of positive selection in Toll-like receptor (TLR) genes in mammals. BMC Evol Biol 11: 368.

24. Huang Y, Temperley ND, Ren L, Smith J, Li N, et al. (2011) Molecular evolution of the vertebrate TLR1 gene family-a complex history of gene duplication, gene conversion, positive selection and co-evolution. BMC Evol Biol 11: 149.

25. Barreiro LB, Ben-Ali M, Quach H, Laval G, Patin E, et al. (2009) Evolutionary dynamics of human Toll-like receptors and their different contributions to host defense. PLoS Genet 5: e1000562.

26. Wlasiuk G, Nachman MW (2010) Adaptation and constraint at Toll-like receptors in primates. Mol Biol Evol 27: 2172-2186.

27. Huson DH, Bryant D (2006) Application of phylogenetic networks in evolutionary studies. Molecular biology and evolution 23: 254-267.

28. Wang J, Zhang Z, Liu J, Zhao J, Yin D (2016) Ectodomain Architecture Affects Sequence and Functional Evolution of Vertebrate Toll-like Receptors. Scientific reports 6: 26705 .

29. Fatemi K, Radvar M, Rezaee A, Rafatpanah H, Azangoo khiavi H, et al. (2013) Comparison of relative TLR-2 and TLR-4 expression level of disease and healthy gingival tissue of smoking and non-smoking patients and periodontally healthy control patients. Aust Dent $\mathrm{J} 58$ : 315-320.

30. Jin MS, Kim SE, Heo JY, Lee ME, Kim HM, et al. (2007) Crystal structure of the TLR1-TLR2 heterodimer induced by binding of a tri-acylated lipopeptide. Cell 130: 1071-1082.

31. Hamann L, Kupcinskas J, Berrocal Almanza LC, Skieceviciene J, Franke A, et al. (2015) Less functional variants of TLR-1/-6/-10 genes are associated with age. Immun Ageing 12: 7.

32. Lang D, Lu MM, Huang L, Engleka KA, Zhang M, et al. (2005) Pax3 functions at a nodal point in melanocyte stem cell differentiation. Nature 433: 884-887.

33. Anttila JE, Whitaker KW, Wires ES, Harvey BK, Airavaara M (2016) Role of microglia in ischemic focal stroke and recovery: focus on Tolllike receptors. Progress in neuro-psychopharmacology \& biological psychiatry 79: 3-14

34. Heuking S, Rothen-Rutishauser B, Raemy DO, Gehr P, Borchard G (2013) Fate of TLR-1/TLR-2 agonist functionalised pDNA nanoparticles upon deposition at the human bronchial epithelium in vitro. $\mathrm{J}$ Nanobiotechnology 11: 29 . 
Citation: Hong W, Zhang L, Chen P, Dai S, Xia Y, et al. (2018) Staphylococcal Enterotoxins Modulated the Porcine Toll-Like Receptor Transcription and Medicated Inflammatory Response. Arch Vet Sci Technol: AVST-141. DOI: 10.29011/AVST-141. 100041

35. Kang JY, Nan X, Jin MS, Youn SJ, Ryu YH et al. (2009) Recognition of lipopeptide patterns by Toll-like receptor 2-Toll-like receptor 6 heterodimer. Immunity 31: 873-884.

36. Han S, Xiao Y, Zheng D, Gu Y, Xuan Y, et al. (2016) Establishment and application of a competitive enzyme-linked immunosorbent assay differentiating PCV2 antibodies from mixture of PCV1/PCV2 antibodies in pig sera. BMC Vet Res 12: 175.

37. Lahiri R, Derwa Y, Bashir Z, Giles E, Torrance HD, et al. (2016) Systemic Inflammatory Response Syndrome After Major Abdominal Surgery Predicted by Early Upregulation of TLR4 and TLR5. Annals of surgery 263: 1028-1037.

38. Ohto U, Yamakawa N, Akashi-Takamura S, Miyake K, Shimizu T (2012) Structural analyses of human Toll-like receptor 4 polymorphisms D299G and T399I. The Journal of biological chemistry 287: 40611-40617.

39. Bell JK, Botos I, Hall PR, Askins J, Shiloach J, et al. (2005) The molecular structure of the Toll-like receptor 3 ligand-binding domain. Proceedings of the National Academy of Sciences of the United States of America 102: 10976-10980.

40. Liu L, Botos I, Wang Y, Leonard JN, Shiloach J, et al. (2008) Structural basis of toll-like receptor 3 signaling with double-stranded RNA. Science 320: 379-381.

41. Wei T, Gong J, Jamitzky F, Heckl WM, Stark RW, et al. (2009) Homology modeling of human Toll-like receptors TLR7, 8, and 9 ligandbinding domains. Protein science: a publication of the Protein Society 18: $1684-1691$.
42. Tanji H, Ohto U, Shibata T, Miyake K, Shimizu T (2013) Structural reorganization of the Toll-like receptor 8 dimer induced by agonistic ligands. Science 339: 1426-1429.

43. Pahwa R, Nallasamy P, Jialal I (2016) Toll-like receptors 2 and 4 mediate hyperglycemia induced macrovascular aortic endothelial cell inflammation and perturbation of the endothelial glycocalyx. Journal of diabetes and its complications 30: 563-572.

44. Raja A, Vignesh AR, Mary BA, Tirumurugaan KG, Raj GD, et al. (2011) Sequence analysis of Toll-like receptor genes 1-10 of goat (Capra hircus). Veterinary immunology and immunopathology 140: 252-258.

45. Chang JS, Russell GC, Jann O, Glass EJ, Werling D, et al. (2009) Molecular cloning and characterization of Toll-like receptors 1-10 in sheep. Veterinary immunology and immunopathology 127: 94-105.

46. White SN, Taylor KH, Abbey CA, Gill CA, Womack JE (2003) Haplotype variation in bovine Toll-like receptor 4 and computational prediction of a positively selected ligand-binding domain. Proceedings of the National Academy of Sciences of the United States of America 100: 10364-10369.

47. Vidlak D, Mariani MM, Aldrich A, Liu S, Kielian T (2011) Roles of Tolllike receptor 2 (TLR2) and superantigens on adaptive immune responses during CNS staphylococcal infection. Brain Behav Immun 25: 905-914.

48. Li Y, Deng H, Shi PD, Xu DD, Zhang LL, et al. (2017b) Toxic effects of seu are different from those of other staphylococcal enterotoxins. American journal of translational research 9: 1618-1629. 